0

GeORgE Fox

UNIVERSITY
Digital Commons @ George Fox University

2005

Enhancing Academic Engagement: Providing Opportunities for Responding and Influencing Students to Choose to Respond

Danielle N. Pappas

C. H. Skinner

K. A. Davis 


\title{
ENHANCING ACADEMIC ENGAGEMENT: PROVIDING OPPORTUNITIES FOR RESPONDING AND INFLUENCING STUDENTS TO CHOOSE TO RESPOND
}

CHRISTOPHER H. SKINNER, DANIELLE N. PAPPAS, AND KAI A. DAVIS

The University of Tennessee

\begin{abstract}
Although educators often provide opportunities for students to engage in active academic responding, in many situations, students either cannot or will not respond. In the current article, we analyze the reasons students fail to respond. Practical procedures educators can use to prevent can't do problems are provided. Won't do problems are conceptualized as choice behaviors. Both applied and theoretical research on choice behavior provides the basis for recommendations designed to enhance the probability of students choosing to engage in active accurate academic (AAA) responding. Such procedures can increase skill development and achievement while decreasing inappropriate behaviors that are incompatible with AAA responding. School psychologists may utilize this information during the initial stages of collaborative problem solving (e.g., consultation) to help conceptualize problems. This conceptualization may then guide the assessment and intervention processes. (C) 2005 Wiley Periodicals, Inc.
\end{abstract}

Haring and Eaton (1978) developed a hierarchy of skill development. Initially, the focus is on acquisition, and the goal is to occasion accurate responding. After students acquire skills, the focus shifts to enhancing skill fluency, or automaticity (i.e., speed of accurate responding), and maintenance. Researchers have shown that fluency and maintenance are enhanced when students engage in high rates of active accurate academic (AAA) responding (e.g., Berliner, 1984; Greenwood, Delquadri, \& Hall, 1984; Skinner, Belfiore, Mace, Williams, \& Johns, 1997). Thus, educators often plan or assign activities designed to occasion AAA responding, including independent seat work (ISW), recitation sessions, and homework; however, when provided with opportunities to engage in AAA responding, often students can't or won't respond.

Skinner (2004) provided an overview of recommendations for enhancing academic engagement. ${ }^{1}$ The current article provides a more detailed analysis of choice behaviors and a more comprehensive review of basic and applied research supporting recommendations for enhancing academic engagement, developing skills, and reducing undesirable behaviors. Various reasons why students can't or choose not to engage in assigned academic tasks are described and analyzed. Additionally, strategies and procedures that can be used to enhance students' AAA responding in classrooms are provided.

\section{Can't do Problems}

There are instances when students can't engage in AAA responding because they do not (a) have the materials necessary to do assigned work, (b) understand the assignments, (c) have sufficient time to respond, and/or (d) have the prerequisite skills needed to respond accurately (Skinner, 2004). Table 1 summarizes these problems and the procedures that can be used to address them.

\section{Missing Materials}

Can't do problems occur when students do not have the materials required to do assigned work. This can frustrate teachers, who sometimes refuse to provide the misplaced, destroyed,

Correspondence to: Christopher H. Skinner, College of EHHS, Claxton Complex A-518, The University of Tennessee, Knoxville, TN 37996-3452. E-mail: cskinne1@utk.edu

${ }^{1}$ Copyright 2004 by the National Association of School Psychologists. Adapted with permission of the publisher. 


\begin{tabular}{|c|c|}
\hline Cause & Solution \\
\hline Missing materials & $\begin{array}{l}\text { - Give students the needed materials and devise other consequences for irresponsible } \\
\text { behavior (e.g., coming to class unprepared). }\end{array}$ \\
\hline Does not understand & $\begin{array}{l}\text { - Encourage students to ask for help (clarification). } \\
\text { - During ISW of small-group activities, circulate around the room to ensure students are } \\
\text { engage in AAA responding. } \\
\text { - Review and reteach when students do not understand. }\end{array}$ \\
\hline Needs more time & $\begin{array}{l}\text { - Provide more time. } \\
\text { - Assignment briefer, but multiple assignments. } \\
\text { - Set time limits, provide more work than they can complete, and positively reinforce for } \\
\text { amount of work completed. }\end{array}$ \\
\hline Lack prerequisite skills & $\begin{array}{l}\text { - Remedy skill deficits. } \\
\text { - Implement accommodation procedures that allow student to learn, even with these } \\
\text { deficits. }\end{array}$ \\
\hline
\end{tabular}

stolen, or simply forgotten materials. It is understandable that educators would allow natural consequences to punish students' behavior. For example, the class is given an ISW assignment that requires each student to complete two workbook pages. Because John left his workbook at home, he cannot complete the assignments and receives a letter grade of $F$ or percent grade of 0 for this assignment; however, preventing students from engaging in assigned academic tasks because they forgot materials has several important negative side effects. Because students are prevented from engaging in AAA responding, their learning or skill development may be depressed (Berliner, 1984; Greenwood et al., 1984). This strategy also may teach students that doing assigned academic work is not very important. With no opportunity to engage in assigned academic tasks, requiring students to sit passively, knowing that they are going to fail, may cause negative emotional reactions and inappropriate behaviors (Romeo, 1998). These reactions may be more likely to occur in students who are motivated to complete assignments. Perhaps a more serious situation occurs with students who are negatively reinforced by being able to escape or avoid academic work (Gresham, Watson, \& Skinner, 2001). In these instances, allowing students to avoid work may strengthen or reinforce the behaviors that educators are hoping to punish (i.e., coming to class unprepared).

Although educators are often encouraged to let natural consequences prevail, these negative side effects suggest that when students do not have needed materials, educators should give the students the materials they need to do the work. When rates of coming to class unprepared are extremely high, educators should consider using other procedures that do not decrease AAA responding to address irresponsible behaviors (e.g., loss of privileges).

\section{Don't Understand Assignments}

Can't do problems also occur when students do not understand assignments. This may occur when students are given ISW assignments after teacher-led instruction. In these situations, students may raise their hands and ask for help (e.g., clarification, additional instruction). This should be encouraged, as teachers often can quickly review the assignment and then the student can begin AAA responding. 
In some instances, teachers may suspect that the reason a student does not understand what is expected is because he or she was not paying attention during preceding lessons. In these instances, teachers may be concerned that providing additional instruction will reinforce inappropriate behavior (i.e., inattention). While this may be true, it is critical that educators avoid discouraging students from asking for help. Otherwise, educators may not notice that assignments were misunderstood until a student turns in an assignment with few, if any, AAA responses. If a student develops a pattern of always asking for help, educators should consider enhancing reinforcement when the student attends and works independently without additional assistance (i.e., differential reinforcement).

Sometimes students are not aware that they are responding inappropriately. In other cases, students may know that they are responding inappropriately, but fail to ask for help because they are afraid that their teacher will punish them (e.g., publicly humiliate the students for inaccurate responding). Regardless, these situations result in lower levels of AAA responding. To prevent this from occurring, teachers often circulate around the room as students are working, monitoring their performance and providing corrective feedback when necessary. Peer monitoring, self-monitoring, and technology also can be used to provide immediate feedback (Greenwood, Delquadri, \& Carta, 1997; Henington \& Skinner, 1998; Skinner, Shapiro, Turco, Cole, \& Brown, 1992; Skinner \& Smith, 1992).

When circulating around the room, teachers should not ignore students who are engaged in high rates of AAA responding. Instead, they should reinforce students for engaging in desired behaviors. One concern is that delivering this reinforcement (e.g., praise) can disrupt the student's AAA responding. Thus, reinforcement should be brief and nondisruptive (Daly, Chafouleas, \& Skinner, 2005). For example, a smile and the statement "good job" may prove less disruptive than long, effusive, labeled praise (e.g., "Johnny, I really like how well you are working! This is exactly what everyone needs to be doing. Give me a 'high five.'”).

\section{Not Enough Time}

Can't do problems also occur when students do not have time to accurately complete assignments or tasks. For example, a teacher may be leading a recitation session during which students raise their hands to answer questions. Because the goal is to have each member of the class cognitively respond to each question, teachers rarely call on a student before asking a question, as this would encourage only the student who was called upon to respond (Rowe, 1974). A similar situation occurs when the interval between the question being asked and the answer being provided (i.e., wait time) is too brief. Once a student provides the correct answer, peers who are in the process of responding but have not yet finished responding typically stop attempting to form an accurate response (Riley, 1986; Rowe, 1974). Because time needed to respond varies among students and across questions, teachers should not call on the first person to raise his or her hand; instead, they should give the entire class time to respond (Rowe, 1974).

Recitation management procedures can increase class-wide AAA responding; however, because only the called-upon student provides overt responses, it is not possible to ensure that each student is responding. One solution is to provide students with a mechanism for overt responding. For example, after a question is asked, students can write their responses on cards and then raise their hands with their responses facing the teacher. Using response cards or Mylar dry-erase boards to increase the probability of students responding allows educators to evaluate the accuracy of those responses. The observable inaccurate responses provide educators with feedback that not only may suggest the need to clarify or reteach but also the type of reteaching or clarification that is needed to prevent future inaccurate responding (e.g., Grskovic \& Belfiore, 1996; Heward \& Gardner, 1996; Maheady, Michielli-Pendl, Mallette, \& Harper, 2002). 
When ISW is assigned, all students often receive the same assignment and the same amount of time allotted to complete it. In this situation, some students finish assignments before others, and some students may not be able to finish within the allotted time. When assignments are composed of similar discrete tasks, one strategy to address this concern is altering assignments so that they include an unlimited amount of work or more work than any student can complete. Educators then reinforce each student based on the amount and quality of the work that they accurately complete (i.e., reinforcement contingent upon the number of AAA responses). One example of a system that employs this strategy is Class-Wide Peer Tutoring (Greenwood et al., 1997).

A second strategy is to make assignments brief so that more students can complete them. After a student completes an assignment, he or she can then be allowed to engage in other activities that enhance learning such as working in learning centers, helping peers, or even completing another brief assignment. Wallace, Cox, and Skinner (2003) showed that providing multiple briefer assignments, as opposed to one long assignment, and reinforcing assignment completion enhanced academic engagement and rates of AAA responding. Additionally, reinforcing students for assignment completion may enhance persistence and improve student perceptions of both current and future assignments (Skinner, 2002).

\section{Lacks Prerequisite Skills}

The most serious can't do problem occurs when a student understands what to do, but lacks the prerequisite skills to complete assigned tasks. This problem requires remediation and/or accommodation procedures. Attempts to remedy skill deficits often require an assessment of prerequisite skills to identify those mastered and those in need of more development. Curriculum-Based Assessment and Curriculum-Based Measurement procedures have been designed to identify skill deficits (Gravois \& Gickling, 2002; Shapiro, 1996; Shinn, 2002). Educators then must implement strategies that allow students to learn or relearn these skills or to learn despite these skill deficits (i.e., accommodation procedures). Numerous intervention procedures have been shown to remedy skill deficits or allow students to learn despite deficits (e.g., Joseph, 2002; Wise Berninger, 2002). As it is beyond our scope here to address these assessment, remediation, and/or accommodation processes and procedures, the remainder of this article will focus on won't do problems.

\section{Won't Do Is Choice}

Educators and parents often express concern over the choices that children make. Much of this concern involves specific, conscious choices that can have immediate aversive effects on a child's life and those in her or his community (e.g., playing with matches, failing to look both ways when crossing the street). Adults often attempt to influence children to avoid choosing to engage in behaviors that present a clear and present danger. Within classroom environments, students make choices of a very different nature. If a student can do assigned academic work, academic engagement is a matter of choice (Skinner, Wallace, \& Neddenriep, 2002). Choosing to engage in academic work is important because these behaviors aid in skill development and learning; however, this type of choice behavior differs from choosing not to engage in dangerous or harmful behaviors. Table 2 summarizes these differences.

Imagine a teacher surveying his or her students' behavior on the playground and observing two students playing with matches. We tend to view this behavior-choosing to play with matches - as a discrete and conscious choice. Choosing to engage in assigned academic tasks are often continuous behaviors as opposed to discrete behaviors. In many instances, students are not aware or conscious of these choice behaviors. For example, a teacher may assign reading, and John may begin reading. He has chosen to engage in the assigned work; however, at any given 


\begin{tabular}{|c|c|}
\hline Temporal characteristics & Discrete choice. \\
\hline Physical characteristics & Conscious choice. \\
\hline Behavior valence & $\begin{array}{l}\text { Choosing to engage in } \\
\text { inappropriate behavior. }\end{array}$ \\
\hline Effects of choice & $\begin{array}{l}\text { May have a serious, immediate, } \\
\text { and long-term harmful effect. }\end{array}$ \\
\hline $\begin{array}{l}\text { Contingent relationship } \\
\text { between choice and } \\
\text { consequences }\end{array}$ & $\begin{array}{l}\text { Clear causal connection between } \\
\text { behavior and immediate } \\
\text { consequences. }\end{array}$ \\
\hline $\begin{array}{l}\text { Additional consequences: } \\
\text { Adult reaction }\end{array}$ & $\begin{array}{l}\text { Behavior typically punished by } \\
\text { adults. }\end{array}$ \\
\hline $\begin{array}{l}\text { Additional consequences: } \\
\text { Peer reaction }\end{array}$ & $\begin{array}{l}\text { Young children often tattle while } \\
\text { older children may positively } \\
\text { reinforce these behaviors. }\end{array}$ \\
\hline
\end{tabular}

Continuous, at any time can choose to stop engaging in work.

Often an unconscious choice that requires less cognitive energy.

Choosing to engage in appropriate behavior.

Delayed effect that can significantly increase quality of life.

Causal connection between behavior and consequences is delayed and less clear.

Behavior often ignored by adults as students are doing what they should be doing.

Behavior typically ignored by peers.

reinforce these behaviors.

moment in time (continuous choice), John can cease reading and engage in another behavior (e.g., begin thinking about what he is going to have for lunch). While John's behavior may not have taken a large amount of time or cognitive resource (some might call it an unconscious choice), it is still choice behavior (Skinner, Wallace, \& Neddenriep, 2002).

In other ways, choosing to engage in assigned academic tasks is different from choosing to engage in behaviors that present a clear and present danger. First, there is behavior valence. Because we want to increase the probability that students will choose to engage in assigned work (i.e., the behavior has a positive valence) and decrease the probability that students choose to engage in dangerous behaviors (i.e., negative valence behaviors), different procedures will often ${ }^{2}$ be used to address these behaviors.

These two classes of behavior also differ in the manner in which they operate on their environment. Dangerous behaviors often have an obvious, direct, and immediate aversive effect on self or others (e.g., playing with matches causes children to burn themselves and the school). Choosing to engage in AAA responding often increases learning and skill development (Skinner, Fletcher, \& Henington, 1996). While this is a direct effect, it is less obvious. Over time, however, children who repeatedly choose to engage in assigned schoolwork are likely to have stronger academic skill development, which may enhance their quality of life and socioeconomic status (SES) as adults. Adult SES has been used to predict an abundance of outcomes (e.g., health, use of illicit drugs, mental illness) for both adults and their children. Thus, like choosing not to engage in behaviors that represent a clear and present danger to self or others, choosing to engage in assigned

\footnotetext{
${ }^{2}$ There are some procedures (e.g., self-monitoring) that can be used to increase positive valence behaviors and decrease negative valence behaviors.
} 
academic tasks represents important choice behaviors that can have a significant impact on society in general and on quality of life for both students and future generations (i.e., the children that the students may eventually parent).

Finally, adults and peers often react differently to these two classes of choice behavior. Adults will typically punish dangerous behaviors (e.g., Scott, Liaupsin, Nelson, \& McIntyre, in press). Younger peers may inform on children who engage in these behaviors (e.g., tattle), but older peers may ignore or encourage these behaviors (Henington \& Skinner, 1998). When students choose to engage in assigned academic tasks, adults often ignore this behavior, as students are doing what they are supposed to do (O'Leary, Poulos, \& Devine, 1972). Additionally, unless peers have a vested interest in their classmates' learning and academic performance (e.g., interdependent group contingency), classmates will typically ignore peers who choose to engage in assigned work (Slavin, 1991).

When academic engagement is viewed as a choice, several empirically supported theories and strategies can be applied to increase the probability of students choosing to engage in assigned work. These strategies are summarized in Table 3. These principles include providing students with choices and altering reinforcement for engaging in assigned academic tasks and/or reducing reinforcement for competing behaviors.

\section{Empowerment Principle: Providing Students with Choices}

The empowerment principle is based on the premise that giving students choices in their academic assignments (empowering students) will increase the probability of them choosing to engage in assigned work. Researchers have found that students are more likely to be academically engaged and less likely to choose to engage in inappropriate behaviors when they are allowed to choose their assignments (Dunlap et al., 1994; Dunlap \& Kern, 1996). Examples on how to provide assignment choice in the classroom are provided in Dunlap et al. (1994) and Dunlap \& Kern (1996).

While providing choices of academic assignments can be effective, as with all other behaviors, choice must be limited. Providing choices of academic assignments is most appropriate when

Table 3

Won't Do

Cause

Solution

Assigned academic work takes too much effort.

Reinforcement for engaging in academic work is too thin, (i.e., too infrequent) relative to reinforcement for competing behaviors.

Reinforcement is low quality.
- Break long assignment into multiple brief assignments.

- Allow assignment choices.

- Intersperse brief tasks among tasks that take more time to complete.

- Enhance rates of reinforcement (e.g., more frequent praise).

- Break long assignments into multiple brief assignments.

- Intersperse brief tasks among tasks that require more time to complete.

- Cue more rapid responding (e.g., use a stopwatch).

- Reinforce based on amount of work completed.

- Reduce rate of positive reinforcement for competing behaviors.

- Generate a pool of reinforcers and allow students to randomly select reinforcers.

- Allow students to contribute to the reinforcer pool or choose reinforcement.

- Consider using exchangeable reinforcers (e.g., tokens) that allow student to select idiosyncratic high-quality reinforcers. 
all choice options will result in equivalent learning. After all, some students may never choose to engage in mathematics assignments. Additionally, when assignments are not equivalent (e.g., two different math assignments), the principle of least effort suggests that providing choices may retard some students' learning. This will be addressed further in the next section.

In addition to providing assignment choices, educators can apply the empowerment principle to several other aspects of assignments. For example, educators could empower students by allowing them to choose reinforcers that are delivered contingent upon academic performance (Popkin \& Skinner, 2003). Additionally, educators could allow students to participate in scheduling academic activities (e.g., mathematics before reading or vice versa) or give them different response options on assignments (e.g., working on computers vs. paper and pencil). These procedures may encourage students to engage in assigned activities without reducing learning.

\section{Principle of Least Effort}

When given the choice of two behaviors, and all else is held constant, living organisms (including students) will choose to engage in the behavior that requires the least effort (Billington \& Ditommaso, 2003). This principle accounts for much of our technological progress and explains why we have washing machines, elevators, automobiles, and so on; however, within classrooms, it means that when educators provide students with assignment options, students are more likely to choose the assignment that requires the least amount of effort as opposed to the more challenging assignment that may enhance their learning and/or skill development to a greater degree ${ }^{3}$ (Billington \& Skinner, 2002; Cates \& Skinner, 2000). Although researchers have found that students may prefer and be more likely to choose to work on less challenging or briefer assignments (e.g., Billington, Skinner, \& Cruchon, 2004; Billington, Skinner, Hutchins, \& Malone, 2004; Cooke, Guzaukas, Presley, \& Kerr, 1994; Winterling, Dunlap, \& O'Neill, 1987), reducing assignment demands can reduce learning rates (MacQuarrie, Tucker, Burns, \& Hartman, 2002; Roberts, Turco, \& Shapiro, 1991).

For example, a tenth-grade student named Trey who had emotional-behavioral disorders began the school year with his Individualized Education Program (IEP) placing him in the beginning of the third-grade reading curricula. When given reading assignments, he would choose to engage in other behaviors (e.g., put his head down, throw his reading book). One hypothesis was that he was misplaced, and a solution was to place him in the second-grade-level reading curriculum. A review of Trey's individual education plans from the last several years showed that each year he was placed in the third-grade reading curricula but was then switched to the second-grade curricula after several weeks of inappropriate behavior during reading. It appeared that Trey had learned a strategy that allowed him to receive lower effort assignments. While Trey may not have been consciously or intentionally applying this strategy, he was still choosing not to read the more difficult material. These choice behaviors resulted in Trey falling further behind in his reading skill development. The third general principle, altering relative reinforcement, can be used to address this problem.

\footnotetext{
${ }^{3}$ We are not stating or implying that students will never choose to engage in behaviors that require more effort. Each student's learning history results in some behaviors being higher probability behaviors, which can actually serve as reinforcers (Premack, 1965). Thus, a student may choose to engage in more interesting tasks that require more effort; however, in this situation all else is not equal, as engaging in the more interesting task is associated with greater reinforcement than is engaging in the less interesting task. Additionally, even the opportunity to engage in low probability behaviors (e.g., less interesting tasks) can be used to reinforce engagement in higher probability behaviors (e.g., more interesting) when the opportunity to engage in low probability behaviors has bee been restricted (Timberlake \& Farmer-Dougan, 1991).
} 


\section{Principle of Relative Reinforcement}

In classrooms, the number of competing behaviors in which students can choose to engage is infinite. A student could choose to do assigned work, gaze at his book while thinking about lunch, throw a tantrum, scribble on his shoe, and so on. Richard Herrnstein (1961) showed us that choice behavior is predictable and influenced by relative, as opposed to absolute, reinforcement. More recently, researchers showed that when provided with a choice of two or more behaviors, with all else held constant, students are more likely to choose to engage in the behavior that results in more immediate reinforcement, higher rate reinforcement, or higher quality reinforcement (Mace, McCurdy, \& Quigley, 1990; Martens, Halperin, Rummel, \& Kilpatrick, 1990; Neef, Mace, \& Shade, 1993; Neef, Mace, Shea, \& Shade, 1992; Neef, Shade, \& Miller, 1994). Thus, educators can increase the probability of students choosing to engage in assigned work by both enhancing reinforcement for assigned tasks and weakening reinforcement for competing behaviors (Martens \& Houk, 1989; Martens, Lochner, \& Kelly, 1992; Myerson \& Hale, 1984).

Imperfect extinction. Often, educators focus on reducing reinforcement for competing alternative behaviors by attempting to put these behaviors on extinction (e.g., stop reinforcement for these behaviors). While desirable, extinction is difficult, if not impossible, within educational settings. Consider the class clown who chooses to engage in disruptive behaviors that are reinforced with attention or laughing. No teacher can consistently ignore such behaviors, and despite their best efforts, they occasionally laugh in response to these behaviors. Even if a teacher could implement perfect extinction, it is not possible to control each classmate's response to these inappropriate behaviors (Skinner, Waterson, et al., 2002).

One concern with not being able to implement perfect extinction is that providing reinforcement less frequently (thin schedules) and intermittently (variable schedules) will serve only to maintain the behavior (Skinner, Waterson, et al., 2002). While this concern has some merit, because choice behavior is based on relative reinforcement strength for competing behaviors, perfect extinction is not necessary. Rather, altering the classroom contingencies so that reinforcement for academic responding is superior to reinforcement for alternative competing responding should be sufficient to increase the probability of students choosing to respond to academic tasks (Martens \& Houk, 1989; Martens et al., 1992; Myerson \& Hale, 1984). This suggests that perfect extinction is not necessary because the probability of students choosing to engage in assigned academic tasks can be increased by enhancing reinforcement for academic responding (Skinner, Wallace, \& Neddenriep, 2002).

\section{Strengthening Reinforcement for AAA Responding}

There are many strategies that can be used to enhance reinforcement for AAA responding and consequently enhance the probability of students choosing to engage in academic responding. Next, we will address some of these procedures by examining reinforcement components including target behaviors, criterion, and reinforcers that should be considered when attempting to enhance reinforcement for academic responding.

\section{Target Behaviors}

Much emphasis is placed on reinforcing students' performance on exams; however, exams typically provide students with few opportunities to respond. Thus, although exams may be effective for measuring learning, they are not the primary cause of learning. Educators also should reinforce student behaviors that cause learning or strong performance on exams. To provide this reinforcement, teachers must identify the target behaviors that they are going to reinforce. 
Academic engagement can be covert (e.g., listening to a lecture) or overt (e.g., responding to a question in writing or verbally). Overt responding is preferable to covert responding because educators can (a) ensure that students are responding, (b) reinforce accurate responding, and (c) remedy inaccurate responding (Skinner, Dittmer, \& Howell, 2000); however, covert responding can require less effort and allow for more rapid rates of responding (Skinner, Bamberg, Smith, \& Powell, 1993). Therefore, educators should attempt to reinforce both forms of responding. When responses are overt, AAA responding can be directly observed and reinforced. When responding is covert, frequent assessments of skill development should be implemented, and educators should then indirectly reinforce covert responding by reinforcing learning as measured by student overt responding during these assessments (Skinner \& Smith, 1992).

When educators can increase the number of AAA responses in a fixed period of time, they also can increase learning rates (Skinner et al., 1997). Thus, in addition to focusing on increasing the number of AAA responses, educators also should focus on rates of AAA responding (Skinner, Belfiore, \& Watson, 1995/2002).

Several procedures have been shown to enhance rates of responding without sacrificing accuracy (Skinner, Fletcher, \& Henington, 1996). Van Houten and Little (1982) found that reducing time available for responding enhanced AAA responding. Thus, rather than providing $30 \mathrm{~min}$ to complete one assignment, educators should consider providing $10 \mathrm{~min}$ to complete three briefer assignments (Wallace et al., 2003). Additionally, prompting or cueing students to respond more rapidly can enhance rates of accurate academic responding. Cueing procedures can be as simple as starting a stopwatch in plain view of the students when you tell them to begin (Derr \& Shapiro, 1989; Derr-Minneci \& Shapiro, 1992; Evans, Skinner, Henington, Sims, \& McDaniel, 2002). Providing temporal prompts as the students are working (e.g., having students underline the last problem completed as each minute has passed) also has been shown to enhance AAA responding rates (Rhymer, Henington, Skinner, \& Looby, 1999; Rhymer, Skinner, Henington, D'Reaux, \& Sims, 1998; Van Houten, Morrison, Jarvis, \& McDonald, 1974; Van Houten \& Thompson, 1976). Altering response topography has been shown to enhance AAA responding rates. For example, allowing students to respond verbally, as opposed to writing responses, can enhance response rates (Skinner et al., 1997). Using response cards, as opposed to having students raise hands and answer questions, can enhance response rates across the entire class (Maheady et al., 2002).

\section{Criteria}

While establishing target behaviors is important, it also is critical to set appropriate criteria. Setting appropriate criteria is difficult, especially when independent group reinforcement is used. With independent group reinforcement, target behaviors, criterion, and reinforcers are the same for all members of the group (group aspect), but reinforcement is delivered to each student contingent upon his or her own responding (independent aspect of the contingency). Because they are considered fair (Turco, Elliott, \& Witt, 1985), independent group reinforcement programs are often used when targeting academic behaviors (e.g., grades).

A serious weakness of independent group contingencies is that they are unlikely to be equally effective across students. Assuming consequences for AAA responding are equal across students, those students who require more effort to meet the AAA responding criterion (e.g., those with lower levels of skill development) are less likely to choose to engage in assigned work. Therefore, the students who most need to engage in AAA responding to remedy skill deficits may be the least likely to choose to engage in assigned work (Popkin \& Skinner, 2003).

One solution to this problem is to alter the target behavior and/or criterion for gaining access to reinforcement across students (e.g., establishing individual contingencies for each student); however, setting different target behaviors and criteria for each student is difficult, time consum- 
ing, considered unfair, and can cause social problems among classmates (Skinner, Cashwell, \& Dunn, 1996; Skinner, Skinner, \& Sterling-Turner, 2002). In addition, making assignments easier or briefer for students with skill deficits can reduce learning rates in students who already have academic deficiencies. Even when these limitations can be addressed, it is difficult to set a criterion that is just right for each student. Some criteria are too low; the students could do better. Other criteria are too high, and students who think that they cannot meet the criteria do not even attempt to meet it (Popkin \& Skinner, 2003). While previous performance data can help guide these decisions, there is no procedure that allows one to determine a criterion that will maximize a student's performance or a groups' performance.

One strategy to address this concern is to set cumulative criteria. Rather than requiring each student to meet a specific performance criterion, each desired response is summed, and each instance of desired academic behavior brings each student closer to earning the reinforcement. For example, each problem completed accurately on mathematics homework assignments could earn students points to be redeemed for the reinforcer. When a student accumulates $x$ points, he or she would receive access to reinforcement (Sharp \& Skinner, in press). Thus, each AAA response, no matter how many or how few, is reinforced.

Another strategy is to randomly select criteria required to earn reinforcement (Popkin \& Skinner, 2003). Thus, the better students do, the more likely they are to earn reinforcement. Because the specific criterion is not known, each student (those with strong and weak academic skills) may choose to do her or his best. Setting an interdependent group criterion is a procedure that can produce unknown criterion. With these criteria, reinforcement is delivered to the entire class based on a group criterion (e.g., class average), as opposed to individual-performance criteria. Because peers cannot be sure how their classmates are performing, each student is more likely to receive access to reinforcement when doing his or her best and when peers do their best (Popkin \& Skinner, 2003).

\section{Reinforcers}

Educators who object to strengthening reinforcement for desired behaviors may be concerned with the application of powerful (high-quality) tangible reinforcers such as candy or toys (Kohn, 1993; O'Leary et al., 1972). Tangible reinforcers often are used as a part of independent group reinforcement programs because they can be delivered easily to some (those whose performance met criteria) and not others; however, when these programs are implemented, students who did not earn reinforcers may still obtain access to them by stealing them, by purchasing them and bringing them to class, or when peers share them (Skinner, Skinner, et al., 2002). Although teachers generally avoid providing public feedback regarding academic performance, when these procedures are used, students know which classmates performed well and which classmates performed poorly by observing who was given a tangible reinforcer. Thus, those with tangible reinforcers may be labeled as smart and those without them as dumb (Skinner, Cashwell, \& Dunn, 1996).

While tangible reinforcers are often powerful, less powerful reinforcers can be equally effective when they are delivered at higher rates and more immediately (Neef et al., 1994). For many students, praise is a reinforcer; however, students who have poor academic skills often have difficulty earning praise for their academic behavior. Recently, Wallace et al. (2003) showed how educators could address this issue by altering assignments. An elementary student was referred because, when given math assignments containing approximately 30 problems, he would complete only a few of them. Thus, the teacher could not praise his work. The solution was simple: Rather than giving the student one long assignment with 30 problems on a page, a paper cutter was used to make five or six brief assignments. When the student finished the first brief assignment, he raised his hand, the teacher praised him for finishing, slapped his hand once (high five), and gave 
him another brief assignment. When he finished that assignment, he was praised for completing two assignments (two high fives for two assignments), and he was given another brief assignment. This procedure increased rates of reinforcement (social praise) for active responding without reducing assignment demands.

Atypical reinforcers also have been found to be effective. Skinner (2002) summarized a series of studies that supported the hypothesis that when given assignments comprised of many discrete tasks, a completed discrete task is a reinforcer. This means that reinforcement rates for working on academic assignments can be enhanced by increasing discrete task (e.g., math problem) completion rates. One procedure for doing this is to intersperse additional very brief discrete tasks among longer discrete tasks. Such procedures have been shown to enhance on-task levels and the probability of students choosing assignments that require more effort to complete as opposed to less effort (Billington, Skinner, \& Cruchon, 2004; Billington, Skinner, Hutchins, \& Malone, 2004; Cates \& Skinner, 2000; McCurdy, Skinner, Grantham, Watson, \& Hindman, 2001; Meadows \& Skinner, 2002; Skinner, Hurst, Teeple, \& Meadows, 2002).

Some of the most powerful and resource-efficient reinforcers are activities (e.g., playing a game, listening to music during independent seatwork time, going on a field trip). Because it is often difficult to deliver activity reinforcers to some students and not to others, these reinforcers are often used with interdependent group contingencies (Skinner, Cashwell, \& Dunn, 1996). In fact, if students are allowed to help select reinforcers, they often suggest some very creative, resource-efficient ones (e.g., the teacher tap dancing, singing a song, or wearing pajamas to school).

Some consequences are high-quality, powerful reinforcers for some students, but weak reinforcers for others. One solution to this problem is to assemble a pool of reinforcers that contains a variety of consequences. When a student's behavior meets a criterion, the reinforcers can be randomly selected. As long as this pool contains at least one high-quality reinforcer for each student, such a procedure can mitigate the problem of some consequences being high-quality reinforcers for some students, but not others (Skinner, Williams, \& Neddenriep, 2004).

Randomizing all components. Recently, Popkin and Skinner (2003) showed how educators could combine interdependent group contingencies and randomly selected criteria, target behaviors, and reinforcers. Popkin and Skinner began the program by first writing the word spelling and different criteria on 30 index cards (e.g., five cards with $75 \%$ written on them, eight cards with $80 \%$, five cards with $95 \%$ ). At the end of the school day, the teacher randomly selected an index card. If the class's average performance on independent seatwork tasks exceeded the randomly selected criterion, the entire group received access to reinforcement. The students who had done well in spelling improved their performance (e.g., $B$ students became $A$ students). The students who had done poorly showed large increases in their performance (e.g., failing students made $A \mathrm{~s}$ and $B \mathrm{~s}$ ). After several weeks, 30 more cards with mathematics and similar criteria were added to the pool. Now, at the end of the day, reinforcement was delivered for meeting a randomly selected criterion in spelling or math. Spelling performance remained strong, and mathematics also improved. Finally, 30 more cards with grammar and similar criteria written on them were added to the pool. Each student's probability of earning access to reinforcement was enhanced when the class did their best in spelling, mathematics, and grammar. If a student did poorly on one assignment, that student could still help earn reinforcement for the class by doing well on the next assignment.

In the Popkin and Skinner (2003) study, in addition to randomly selecting target behaviors (spelling, math, or grammar) and performance criteria (e.g., class average of 75,85 , or $90 \%$ ), the group reinforcers also were randomly selected. To ensure that, for each student, the reinforcer pool contained some high-quality reinforcers, students were encouraged to offer suggestions for other 
reinforcers as the program continued. This procedure also allowed for an application of the empowerment principle without "watering down" assignment requirements.

\section{CONCLUSION}

Although educators plan for and assign academic work, often students do not engage in assigned work because they can't or won't. In this article, we provided some recommendations regarding procedures that should and should not be used to address can't do problems. We also conceptualized won't do problems as choice, and used both basic and applied research to support procedures designed to enhance reinforcement for students choosing to engage in AAA responding.

Sometimes educators are concerned that students should not be reinforced for doing what they should be doing (i.e., some educators consider reinforcement a bribe; Kohn, 1993). This reminds us of B.F. Skinner's (1956) description of how he used to get angry because his subjects (birds) were not behaving as they should. Research on choice behavior suggests that both B.F. Skinner's birds and educators' students are choosing to do exactly what they should be doing based on relative reinforcement for competing behaviors and the effort required for competing behaviors. By strengthening reinforcement for AAA responding, educators can increase the probability of students choosing to engage in AAA responding. Such procedures can increase skill development, thus making it unnecessary to implement complex and expensive skill remediation and accommodation procedures in the future. Additionally, increasing AAA responding will decrease competing inappropriate behaviors and provide for a classroom environment in which the focus is on reinforcing appropriate behaviors as opposed to punishing undesirable behaviors.

\section{REFERENCES}

Berliner, D.C. (1984). The half-full glass: A review of research on teaching. In P.L. Hosford (Ed.), Using what we know about teaching (pp. 51-85). Alexandria, VA: Association for Supervision and Curriculum Development.

Billington, E.J., \& Ditommaso, N.M. (2003). Demonstrations and applications of the matching law in education. Journal of Behavioral Education, 12, 91-104.

Billington, E.J., \& Skinner, C.H. (2002). Getting students to choose to do more work: Evidence of the effectiveness of the interspersal procedure. Journal of Behavioral Education, 11, 105-116.

Billington, E.J., Skinner, C.H., \& Cruchon, N.M. (2004). Improving sixth-grade students' perceptions of high-effort assignments by assigning more work: Interaction of additive interspersal and assignment effort on assignment choice. Journal of School Psychology, 42, 477-490.

Billington, E.J., Skinner, C.H., Hutchins, H., \& Malone, J.C. (2004). Varying problem effort and choice: Using the interspersal technique to influence choice towards more effortful assignments. Journal of Behavioral Education, 13, 193-207.

Cates, G.L., \& Skinner, C.H. (2000). Getting remedial mathematics students to prefer homework with $40 \%$ more problems? An investigation of the strength of the interspersal procedure. Psychology in the Schools, 37, 339-347.

Cooke, N.L., Guzaukas, R., Presley, L.S., \& Kerr, K. (1994). Effects of using a ratio of new items to review items during drill and practice: Three experiments. Education and Treatment of Children, 16, 213-234.

Daly, E.J., Chafouleas, S., \& Skinner, C.H. (2005). Interventions for reading problems: Designing and evaluating effective strategies. New York: Guilford Press.

Derr, T.F., \& Shapiro, E.S. (1989). A behavioral evaluation of curriculum-based assessment of reading. Journal of Psychoeducational Assessment, 7, 148-160.

Derr-Minneci, T.F., \& Shapiro, E.S. (1992). Validating curriculum-based measurement in reading from a behavioral perspective. School Psychology Quarterly, 7, 2-16.

Dunlap, G., DePerzcel, M., Clark, S., Wilson, D., Wright, S., \& Gomez, A. (1994). Choice making to promote adaptive behavior for students with emotional and behavioral challenges. Journal of Applied Behavior Analysis, 27, 505-518.

Dunlap, G., \& Kern, L. (1996). Modifying instructional activities to promote desirable behavior: A conceptual and practical framework. School Psychology Quarterly, 11, 297-312.

Evans, T., Skinner, C.H., Henington, C., Sims, S., \& McDaniel, E.C. (2002). Conspicuous and covert timing during CBM of mathematics across African-American and Caucasian students: An investigation of situational bias. School Psychology Review, 31, 529-539. 
Gravios, T.A., \& Gickling, E.E. (2002). Best practices in curriculum-based assessment. In A. Thomas \& J. Grimes (Eds.), Best practices in school psychology IV: Vol. 1 (pp. 885-898). Bethesda, MD: National Association of School Psychologists.

Greenwood, C.R., Delquadri, J.C., \& Carta, J.J. (1997). Together we can! Class-wide peer tutoring to improve basic academic skills. Longmont, CO: Sopris West.

Greenwood, C.R., Delquadri, J., \& Hall, R.V. (1984). Opportunity to respond and student academic performance. In W. Heward, T. Heron, D. Hill, \& J. Trap-Porter (Eds.), Behavior analysis in education (pp. 58-88). Columbus, OH: Merrill.

Gresham, F.M., Watson, T.S., \& Skinner, C.H. (2001). Functional behavioral assessment: Principles, procedures, and future direction. School Psychology Review, 30, 156-172.

Grskovic, J.A., \& Belfiore, P.J. (1996). Improving the spelling performance of students with disabilities. Journal of Behavioral Education, 6, 343-354.

Haring, N.G., \& Eaton, M.D. (1978). Systematic instructional procedures: An instructional hierarchy. In N.G. Haring, T.C. Lovitt, M.D. Eaton, \& C.L. Hansen (Eds.), The fourth R: Research in the classroom (pp. 23-40). Columbus, OH: Merrill.

Henington, C., \& Skinner, C.H. (1998). Peer monitoring. In K. Toppins \& S. Ely (Eds.), Peer assisted learning (pp. 237253). Hillsdale, NJ: Erlbaum.

Herrnstein, R.J. (1961). Relative and absolute strength of response as a function of frequency of reinforcement. Journal of the Experimental Analysis of Behavior, 4, 267-272.

Heward, W.L., \& Gardner, R., III. (1996). Everyone participates in this class: Using response cards to increase active student response. Teaching Exceptional Children, 28, 4-10.

Joseph, L.M. (2002). Best practices in planning interventions for students with reading problems. In A. Thomas \& J. Grimes (Eds.), Best practices in school psychology IV: Vol. 1 (pp. 803-816). Bethesda, MD: National Association of School Psychologists.

Kohn, A. (1993). Punished by rewards. Boston: Houghton Mifflin.

Mace, F.C., McCurdy, B., \& Quigley, E.A. (1990). The collateral effect of reward predicted by matching theory. Journal of Applied Behavior Analysis, 23, 197-205.

MacQuarrie, L.L., Tucker, J.A., Burns, M.K., \& Hartman, B. (2002). Comparison of retention rates using traditional, drill sandwich, and incremental rehearsal flash card methods. School Psychology Review, 31, 584-595.

Maheady, L., Michielli-Pendl, J., Mallette, B., \& Harper, G.F. (2002). A collaborative research project to improve the academic performance of a diverse sixth grade science class. Teacher Education and Special Education, 25, 55-70.

Martens, B.K., Halperin, S., Rummel, J.E., \& Kilpatrick, D. (1990). Matching theory applied to contingent teacher attention. Behavioral Assessment, 12, 139-155.

Martens, B.K., \& Houk, J.L. (1989). The application of Herrnstein's law of effect to disruptive and on-task behavior of a retarded adolescent girl. Journal of Applied Behavior Analysis, 51, 17-27.

Martens, B.K., Lochner, D.G., \& Kelly, S.Q. (1992). The effects of variable-interval reinforcement on academic engagement: A demonstration of matching theory. Journal of Applied Behavior Analysis, 25, 143-151.

McCurdy, M., Skinner, C.H., Grantham, K., Watson, T.S., \& Hindman, P.M. (2001). Increasing on-task behavior in an elementary student during mathematics seat-work by interspersing additional brief problem. School Psychology Review, $30,23-32$.

Meadows, S., \& Skinner, C.H. (2002, May). Interspersing additional brief English tasks: Enhancing the educational validity of the interspersal procedure. Paper presented at the annual convention of the Association for Applied Behavior Analysis, Toronto.

Myerson, J., \& Hale, S. (1984). Practical implications of the matching law. Journal of Applied Behavior Analysis, 17, 367-380.

Neef, N.A., Mace, F.C., \& Shade, D. (1993). Impulsivity in students with serious emotional disturbance: The interactive effects of reinforcer rate, delay, and quality. Journal of Applied Behavior Analysis, 26, 37-52.

Neef, N.A., Mace, F.C., Shea, M.C., \& Shade, D. (1992). Effects of reinforcer rate and reinforcer quality on time allocation: Extensions of matching theory to educational settings. Journal of Applied Behavior Analysis, 25, 691-699.

Neef, N.A., Shade, D., \& Miller, M.S. (1994). Assessing influential dimensions of reinforcers on choice in students with serious emotional disturbance. Journal of Applied Behavior Analysis, 27, 575-583.

O’Leary, K.D., Poulos, R.W., \& Devine, V.T. (1972). Tangible reinforcers: Bonuses or bribes. Journal of Consulting and Clinical Psychology, 38, 1-8.

Popkin, J., \& Skinner, C.H. (2003). Enhancing academic performance in a classroom serving students with serious emotional disturbance: Interdependent group contingencies with randomly selected components. School Psychology Review, 32, 271-284.

Premack, D. (1965). Reinforcement theory. In D. Levine (Ed.), Nebraska Symposium on Motivation (Vol. 13, pp. 123180). Lincoln: University of Nebraska Press. 
Rhymer, K.N., Henington, C., Skinner, C.H., \& Looby, E.J. (1999). The effects of explicit timing on mathematics performance in second-grade Caucasian and African-American students. School Psychology Quarterly, 14, 397-407.

Rhymer, K.N., Skinner, C.H., Henington, C., D’Reaux, R.A., \& Sims, S. (1998). Effects of explicit timing on mathematics problem completion rates in African-American third-grade elementary children. Journal of Behavioral Analysis, 31, 673-677.

Riley, J.P. (1986). The effects of teachers' wait-time and knowledge comprehension questions on science achievement. Journal of Research in Science Teaching, 23, 335-342.

Roberts, M.L., Turco, T.L., \& Shapiro, E.S. (1991). Differential effects of fixed instructional ratios on students' progress in reading. Journal of Psychoeducational Assessment, 9, 308-318.

Romeo, F.F. (1998). The negative effects of using a group contingency system of classroom management. Journal of Instructional Psychology, 25, 130-134.

Rowe, M. (1974). Wait-time and rewards as instructional variables, their influence on language, logic, and fate control. Part 1: Wait-time. Journal of Research in Science Teaching, 17, 469-475.

Scott, T.M., Liaupsin, C., Nelson, C.M., \& McIntyre, J. (in press). Alton school district team-based functional behavior assessment as a proactive public school process: A descriptive analysis of current barriers. Journal of Behavioral Education.

Shapiro, E.S. (1996). Academic skills problems: Direct assessment and intervention (2nd ed.). New York: Guilford Press.

Sharp, S., \& Skinner, C.H. (in press). Using interdependent group contingencies with randomly selected criteria and paired reading to enhance class-wide reading performance. Journal of Applied School Psychology.

Shinn, M.R. (2002). Best practices in using curriculum-based measurement in a problem-solving model. In A. Thomas \& J. Grimes (Eds.), Best practices in school psychology IV: Vol. 1 (pp. 671-698). Bethesda, MD: National Association of School Psychologists.

Skinner, B.F. (1956). A case history in scientific method. American Psychologist, 11, 221-233.

Skinner, C.H. (2002). An empirical analysis of interspersal research: Evidence, implications and applications of the discrete task completion hypothesis. Journal of School Psychology, 40, 347-368.

Skinner, C.H. (2004). Academic engagement. In A. Canter (Ed.), Helping children at home and school-II: Handouts from your school psychologist (pp. S3-1-S3-4) Bethesda, MD: National Association of School Psychologists.

Skinner, C.H., Bamberg, H., Smith, E.S., \& Powell, S. (1993). Subvocal responding to increase division fact fluency. Remedial and Special Education, 14, 49-56.

Skinner, C.H., Belfiore, P.J., Mace, H.W., Williams, S., \& Johns, G.A. (1997). Altering response topography to increase response efficiency and learning rates. School Psychology Quarterly, 12, 54-64.

Skinner, C.H., Belfiore, P.B., \& Watson, T.S. (1995/2002). Assessing the relative effects of interventions in students with mild disabilities: Assessing instructional time. Journal of Psychoeducational Assessment, 20, 345-356.15. [Reprinted from Assessment in Rehabilitation and Exceptionality, 2, 207-220.]

Skinner, C.H., Cashwell, C., \& Dunn, M. (1996). Independent and interdependent group contingencies: Smoothing the rough waters. Special Services in the Schools, 12, 61-78.

Skinner, C.H., Dittmer, K., \& Howell, L. (2000). Direct observation in school settings: Theoretical issues. In E.S. Shapiro \& T.R. Kratochwill (Eds.), Behavioral assessment in the schools: Theory, research and clinical foundations (pp. 1945). New York: Guilford Press.

Skinner, C.H., Fletcher, P.A., \& Henington, C. (1996). Increasing learning trial rates by increasing student response rates. School Psychology Quarterly, 11, 313-325.

Skinner, C.H., Hurst, K.L., Teeple, D.F., \& Meadows, S.O. (2002). Increasing on-task behavior during mathematics independent seat-work in students with emotional disorders by interspersing additional brief problems. Psychology in the Schools, 39, 647-659.

Skinner, C.H., Shapiro, E.S., Turco, T.L., Cole, C.L., \& Brown, D.K. (1992). A comparison of self- and peer-delivered immediate corrective feedback on multiplication performance. Journal of School Psychology, 30, 101-116.

Skinner, C.H., Skinner, A.L., \& Sterling-Turner, H.E. (2002). Best practices in utilizing group contingencies for intervention and prevention. In A. Thomas \& J. Grimes (Eds.), Best Practices in School Psychology (4th ed., pp. 817-830). Washington, DC: National Association of School Psychologists.

Skinner, C.H., \& Smith, E.S. (1992). Issues surrounding the use of self-managed interventions for increasing academic performance. School Psychology Review, 21, 202-210.

Skinner, C.H., Wallace, M.A., \& Neddenriep, C.E. (2002). Academic remediation: Educational application of research on assignment preference and choice. Child and Family Behavior Therapy, 24, 51-65.

Skinner, C.H., Waterson, H.J., Bryant, D.R., Bryant, R.J., Collins, P.M., Hill, C.J., et al. (2002). Team problem solving based on research, functional behavioral assessment data, teacher acceptability, and Jim Carey's interview. Proven Practices: Prevention \& Remediation Solutions for Schools, 4, 56-64.

Skinner, C.H., Williams, R.L., \& Neddenriep, C.E. (2004). Using interdependent group-oriented reinforcement to enhance academic performance in general education classrooms. School Psychology Review, 33, 384-397. 
Slavin, R.E. (1991). Cooperative learning and group contingencies. Journal of Behavioral Education, 1, 105-116.

Timberlake, W., \& Farmer-Dougan, V.A. (1991). Reinforcement in applied settings: Figuring out ahead of time what will work. Psychological Bulletin, 110, 379-391.

Turco, T.L., Elliott, S.N., \& Witt, J.C. (1985). Children's involvement in treatment selection: A review of theory and analogue research on treatment acceptability. Programming for Adolescents with Behavioral Disorders, 2, 54-62.

Van Houten, R., \& Little, G. (1982). Increased response rate in special education children following an abrupt reduction in time limit. Education and Treatment of Children, 5, 23-32.

Van Houten, R., Morrison, E., Jarvis, R., \& McDonald, M. (1974). The effects of explicitly timing and feedback on compositional response rate in elementary school children. Journal of Applied Behavior Analysis, 7, 547-555.

Van Houten, R., \& Thompson, C. (1976). The effects of explicit timing on math performance. Journal of Applied Behavior Analysis, 9, 227-230.

Wallace, M.A., Cox, E.A., \& Skinner, C.H. (2003). Increasing independent seat-work: Breaking large assignments into smaller assignments and teaching a student with retardation to recruit reinforcement. School Psychology Review, 23, $132-142$.

Winterling, V., Dunlap, G., \& O'Neill, R.E. (1987). The influence of task variation on the aberrant behaviors of autistic students. Education and Treatment of Children, 10, 105-119.

Wise Berninger, V. (2002). Best practices in reading, writing, and math assessment-intervention links: A systems approach for schools, classrooms, and individuals. In A. Thomas \& J. Grimes (Eds.), Best practices in school psychology IV: Vol. 1 (pp. 851-866). Bethesda, MD: National Association of School Psychologists. 